\title{
Reported benefits of early fetal sex determination
}

\begin{abstract}
The childbearing journey is one that begins long before the birth of the child. Upon the process of conceiving, the next significant factor of pregnancy is identifying the fetus's sex. The traditional method of fetal sex determination is an ultrasound, which may inform the mother of her unborn child's sex at 18 weeks of pregnancy. However, with recent genomic and technological advances, fetal sex can be determined earlier than that which an ultrasound can execute. Gateway Genomics' SneakPeek® Early Gender DNA Test is a product that has achieved this by allowing the early knowledge of the fetus's sex. Expecting mothers who utilize the prenatal gender test can discover the sex of their baby as early as 8 weeks into pregnancy. In order to assess the perceived benefits of early fetal sex determination, Gateway Genomics constructed a study in which postpartum women provided insight into the effect of the early gender test on their pregnancy journey. The survey highlights several possible advantages that the early knowledge of fetal sex can provide to the expecting mother, the family, and friends. Results from the survey confirm that early fetal sex determination does confer various benefits to the childbearing process.
\end{abstract}

\author{
Volume 6 Issue 3 - 2020 \\ Nora Abunadi, Nina Hoang, Haley Milot, \\ Chris Jacob \\ Gateway Genomics, USA
}

Correspondence: Haley Milot, Gateway Genomics, San Diego, California, USA, Email haey@gatewaygenomics.org

Received: May 04, 2020 | Published: June 03, 2020

Keywords: sex determination, parents, pregnancy, childbearing

\section{Introduction}

Fetal sex determination is a momentous event that takes place along one's pregnancy. The knowledge of the fetus's sex at an earlier stage allows parents to prepare for their newborn's arrival, strengthens the mother's bond with her child, and offers time for parents to mentally absorb the growth of their family. Furthermore, a study reported there were several psychological advantages of early prenatal testing, such as "perceived control, normalization of pregnancy, peace of mind, and facilitating decision-making". ${ }^{1}$ The discovery of the fetus's sex allows the restless journey of becoming parents to be more manageable.

There are several resources that families can utilize to determine the fetus's sex. Expecting mothers most commonly visit ultrasounds around " 18 to 20 weeks into pregnancy for the propose of evaluating the baby's due date, informing of multiple pregnancy, identifying placenta location or assessing complications. It may also be possible to determine the sex of the fetus during the ultrasound, however, there are several factors that could influence the gender prediction". In addition, this approach can be limiting for parents, as they are not able to experience the relief of knowing their baby's sex until that period. By being unaware of the fetus's sex for 18 weeks into pregnancy, parents are also restricted on opportunities for planning and preparations.

Gateway Genomics' prenatal technology provides an alternative method for expecting mothers to identify their fetus's sex as early as 8 weeks and with a $99.1 \%$ accuracy rate. ${ }^{3}$ This newer, non-invasive technique enables families to learn the fetus's sex at a much earlier stage in the childbearing process. It has been reported that being able to identify the mere presence of a growing fetus provides benefits such as allowing mothers to bond more readily with their baby. ${ }^{4}$ Accordingly, if the early knowledge of pregnancy can provide benefits to the mother, it can be presumed that early fetal sex determination can produce similar effects as well.

As a provider of an early gender test service, Gateway Genomics aims to measure the perceived benefits of determining the sex of the fetus as early as 8 weeks into pregnancy. In comparison to previous studies on benefits that mothers received from knowing the sex of the baby at 18 weeks from an ultrasound, Gateway Genomics intends to study the benefits of early fetal sex identification. Thus, Gateway Genomics designed a survey to assess the benefits that expecting parents received from using the SneakPeek ${ }^{\circledR}$ Early Gender DNA Test.

\section{Methods}

From August 1, 2019 to August 14, 2019, Gateway Genomics conducted an online survey to evaluate the benefits of early fetal sex determination. Eligible respondents were postpartum mothers who had successfully received a gender result at 8 weeks or later from a SneakPeek ${ }^{\circledR}$ Early Gender DNA Test. Survey participants were given a questionnaire that had a "Select all that apply" format to indicate the benefits they received from early knowledge of the fetus's sex (Table 1). The questions concerned general benefits, benefits on planning or preparation, and benefits received on connections with friends and family. The last portion of the questionnaire consisted of an openended question in which respondents were able to provide additional benefits that were not previously discussed or elaborate on an earlier selection they had made.

\section{Results}

\section{General benefits}

The first question was directed to capture general benefits expectant mothers gained from early knowledge of the fetus's sex (Figure 1). A total of 1,129 participants responded to the question. Participants who partook in the survey were able to select from four possible benefits. At $92.7 \%$, the majority of respondents indicated that they were able to satisfy their curiosity. $51.3 \%$ of mothers stated that they gained a sense of control and peace of mind with their pregnancy. The perceived benefits of the removal of the element of surprise and knowledge of something others didn't have received the same amount of responses $(22.6 \%$ each). 
Table I Survey questionnaire

\begin{tabular}{|c|c|c|}
\hline & \multicolumn{2}{|c|}{ Choices (check all that apply) } \\
\hline Question \#I: General Benefits & $\begin{array}{l}\text { A. } \\
\text { B. } \\
\text { C. } \\
\text { D. }\end{array}$ & $\begin{array}{l}\text { Satisfied my curiosity } \\
\text { Removed the Element } \\
\text { of Surprise at Birth } \\
\text { Gave me a Sense of } \\
\text { Control and Peace of } \\
\text { Mind } \\
\text { Let me/us have } \\
\text { something I/We knew } \\
\text { that others didn't }\end{array}$ \\
\hline $\begin{array}{l}\text { Question \#2: Planning/ } \\
\text { Preparation Benefits }\end{array}$ & $\begin{array}{l}\text { a. } \\
\text { b. } \\
\text { c. } \\
\text { d. }\end{array}$ & $\begin{array}{l}\text { Helped me shop for } \\
\text { the baby } \\
\text { Helped me name the } \\
\text { baby } \\
\text { Helped me bond with } \\
\text { baby } \\
\text { Helped prepare older } \\
\text { sibling(s) }\end{array}$ \\
\hline $\begin{array}{l}\text { Question \#3: Connecting with } \\
\text { Friends and Family Benefits }\end{array}$ & $\begin{array}{l}\text { I. } \\
2 . \\
3 . \\
4 . \\
5 . \\
6 .\end{array}$ & $\begin{array}{l}\text { Helped my partner } \\
\text { connect with the baby } \\
\text { Let grandparents or } \\
\text { other relatives know } \\
\text { Had Gender Reveal } \\
\text { Party } \\
\text { Announced to loved } \\
\text { ones through social } \\
\text { media } \\
\text { Announced to loved } \\
\text { ones through email } \\
\text { Announced to loves } \\
\text { ones through cards }\end{array}$ \\
\hline $\begin{array}{l}\text { Question \#4: Please provide } \\
\text { additional benefits or describe } \\
\text { any of the above further. }\end{array}$ & I) & Free Response \\
\hline
\end{tabular}

\section{General Benefits}

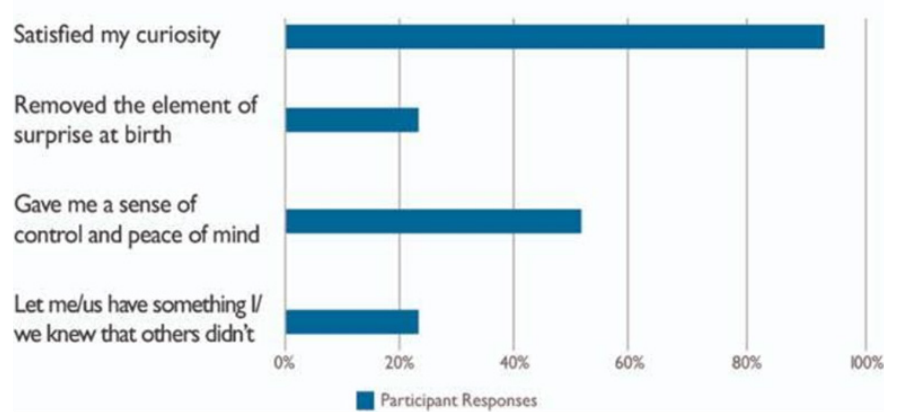

Figure I General benefits of early fetal sex determination.

\section{Planning and/or preparation benefits}

The second question listed on the survey was designed to illustrate how the SneakPeek ${ }^{\circledR}$ Early Gender Test granted easier planning and preparation for expecting mothers and had a total of 1,126 responses (Figure 2). The benefits that scored the highest percentage were shopping for the baby (80.8\%) and naming the baby (80.5\%). 52.6\% of mothers also revealed that they were able to bond with their baby, while $42.5 \%$ noted that they were able to prepare older siblings for the newest arrival in the family upon early knowledge of the fetus's sex.

\section{Planning/Preparation Benefits}

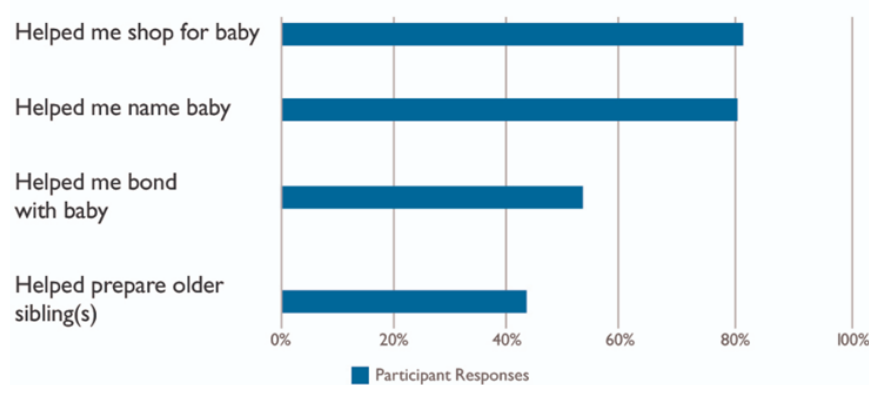

Figure 2 Planning/Preparation benefits of early fetal sex determination.

\section{Connecting with friends and family benefits}

The third question aimed to explore the benefit of connecting with friends and family (Figure 3). A total of 1,113 participants responded to the question. The results revealed that most respondents (71.6\%) found it beneficial to let grandparents and other relatives know the baby's gender as early as possible.

\section{Connecting with Friends and Family}

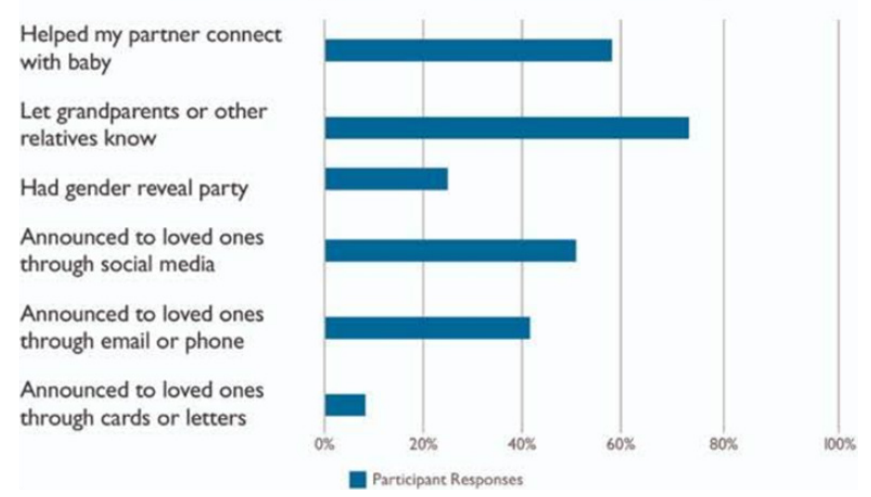

Figure 3 Connecting with friends and family benefits of early fetal sex determination.

\section{Free response}

The fourth question of the survey was formulated as a free response inquiry to allow participants to provide additional benefits they gained from the SneakPeek ${ }^{\circledR}$ Early Gender Test. A substantial number of mothers informed that they did not want to wait for the ultrasound at 18 weeks of gestational age to know the gender of their baby, as some claimed that they were too impatient. Many first-time mothers also stated that they wanted to start preparing early for their baby.

\section{Conclusion}

The purpose of the study conducted by Gateway Genomics was to explore the associated benefits of early fetal determination on various factors of the childbearing process. The study focused on general advantages, planning and preparation benefits, and the ability to connect with friends and family. The four-question survey was completed by a total of 1,129 postpartum mothers that had used the or our SneakPeek ${ }^{\circledR}$ Early Gender DNA Test, and was aimed to assess reasons why mothers would prefer to know the sex of their fetus earlier than that which can be performed by traditional methods. The majority of the respondents in the study indicated that the early knowledge of the fetus's sex was able to satisfy their curiosity. Thus, expecting 
parents desire to know the sex of their baby at the earliest opportunity. The early knowledge was also reported to provide mothers with a sense of control and a peace of mind. This has the potential to reduce possible stress that expecting mothers experience by allowing them to manage their time better. Furthermore, a significant number of mothers reported multiple planning and preparation benefits they received from identifying the fetus's early in the pregnancy journey. Most notably, shopping for the baby and naming the baby received considerable focus. This reveals that, by being informed of the fetus's sex early, mothers can more readily prepare for the baby's arrival. In addition, participants were concerned with the ability of revealing the gender of their baby to friends and family. Upon early knowledge of the fetus's sex, mothers have the advantage of preparing gender parties and connecting with friends and families to deliver the good news.

A few potential limitations of this study should be noted. The questionnaire in this study was short in length and all selections were designed to be positively presented. This may have limited responses as well as potential counterarguments from study participants. Furthermore, the sample population only included mothers who received a gender result from a SneakPeek ${ }^{\circledR}$ test, whereas those who did not receive a conclusive result were not eligible to participate. The results could conceivably have been biased as respondents are more inclined to participate and present positive responses upon receiving a satisfactory test result.
In conclusion, analysis of the survey results reveals diverse reported benefits that mothers have gained from using the SneakPeek ${ }^{\circledR}$ Early Gender DNA Test as an early fetal sex identification device.

\section{Acknowledgments}

None.

\section{Conflicts of interest}

Author declare that there is no conflict of interest.

\section{Funding}

None.

\section{References}

1. Lewis C, Hill M, Skirton H, et al. Non-invasive prenatal diagnosis for fetal sex determination: benefits and disadvantages from the service users' perspective. Eur J Hum Genet. 2012;20(11):1127-1133.

2. Ultrasound: Sonogram. American Pregnancy Association.

3. Casanova J, Cacia S, Milot H, et al. Accurate fetal sex determination from maternal blood at 8 weeks gestation. Int $J$ Pregn \& Chi Birth. 2019;5(4):135-137.

4. Fletcher JC, Evans MI. Maternal bonding in early fetal ultrasound examinations. $N$ Engl J Med. 1983;308(7):392-393. 